\title{
Downregulation of lysine-specific demethylase 1 enhances the sensitivity of hormone-sensitive prostate cancer cells to androgen deprivation therapy
}

\author{
MIN WANG, XIUHENG LIU, ZHIYUAN CHEN, LU ZHANG and XIAODONG WENG \\ Department of Urology, Renmin Hospital of Wuhan University, Wuhan, Hubei 430060, P.R. China
}

Received March 9, 2020; Accepted September 16, 2020

DOI: $10.3892 / 01.2020 .12354$

\begin{abstract}
Lysine-specific demethylase 1 (LSD1) plays an important role in androgen receptor (AR) signaling, and LSD1 levels are associated with prostate cancer (PCa) progression. The present study investigated the association between the downregulation of LSD1 and the proliferation and invasiveness of PCa cells, as well as the effect of LSD1 on the androgen deprivation therapy (ADT)-induced apoptosis of PCa cells. The effect of the inhibition of LSD1 combined with ADT on PCa cell apoptosis was characterized. Furthermore, the mechanisms underlying LSD1-mediated apoptosis induced by ADT in PCa cells were investigated. Downregulation of LSD1 impaired the proliferation and invasiveness of PCa cells. Moreover, downregulation of LSD1 enhanced the apoptosis of PCa cells induced by bicalutamide in vitro. Downregulation of LSD1 decreased PSA expression, increased caspase 3 and Bax expression, decreased Bcl-2 expression and consequently enhanced castration-induced $\mathrm{PCa}$ cell apoptosis in vivo. These findings indicated that downregulation of LSD1 could effectively enhance the efficacy of ADT for hormone- sensitive $\mathrm{PCa}$, demonstrating that this could be a promising adjunctive therapy with ADT for this disease.
\end{abstract}

\section{Introduction}

Worldwide, prostate cancer (PCa) is the second most commonly diagnosed cancer in men, and there were $\sim 1.1$ million diagnoses in 2012 (1). In China, the incidence of PCa is lower compared with that in Western countries (2). However, the incidence of

Correspondence to: Dr Xiuheng Liu, Department of Urology, Renmin Hospital of Wuhan University, 238 Jiefang Road, Wuhan, Hubei 430060, P.R. China

E-mail: doctlxh@163.com

Abbreviations: LSD1, lysine-specific demethylase 1; AR, androgen receptor; $\mathrm{PCa}$, prostate cancer; $\mathrm{ADT}$, androgen deprivation therapy; CRPC, castration-resistant prostate cancer; OS, overall survival

Key words: LSD1, androgen deprivation therapy, hormone-sensitive prostate cancer, apoptosis
PCa is increasing in China, with an estimated 49,000 new diagnoses in 2012, and most of these patients were diagnosed with locally advanced or metastatic PCa (2). Unfortunately, due to late-stage diagnosis, these patients could not undergo radical surgery, and androgen deprivation therapy (ADT) was the standard systemic therapy for this group (2).

Initially, PCa progression is successfully suppressed by ADT, as its growth is dependent on androgens (3). However, almost all cases of advanced $\mathrm{PCa}$ inevitably progresses toward castration-resistant PCa (CRPC) (3). There are several drugs used to treat CRPC. In 2004, docetaxel was approved by the Food and Drug Administration to treat CRPC. In 2010, cabazitaxel and immunotherapy were approved, enzalutamide was approved in 2012 and abiraterone was approved in 2013 (4). Compared with mitoxantrone, docetaxel only extends overall survival (OS) time by 2-2.9 months $(5,6)$. In a randomized phase III trial (PREVAIL) (7), enzalutamide was evaluated in 1,717 patients with chemo-naïve metastatic castration-resistant PCa (mCRPC), and OS was significantly improved but was only extended by 2.2 months [ 32.4 vs. 30.2 months; hazard ratio $(\mathrm{HR})=0.706$; 95\% confidence interval $(\mathrm{CI}), 0.6-0.84 ; \mathrm{P}<0.001)$. In the phase III trial COU-AA-302 $(8,9)$, abiraterone was evaluated in 1,088 patients with chemo-naïve, asymptomatic or mildly symptomatic mCRPC, and OS was significantly improved but was only extended by 4.4 months (34.7 vs. 30.3 months; $\mathrm{HR}=0.81 ; 95 \% \mathrm{CI}, 0.70-0.93 ; \mathrm{P}=0.0033)$. Overall, these results demonstrate that there is no available curative therapy for CRPC. Notably, the lower the early prostate-specific antigen (PSA) level after ADT treatment, the longer the patient's response to ADT is (10). Therefore, treatments that decrease the early PSA level combined with ADT and delay PCa progression to CRPC may extend the OS of patients with PCa.

Previously, it was accepted that lysine methylation was irreversible until lysine-specific demethylase 1 (LSD1) was identified (11). Our previous studies $(12,13)$ and several others (14-16) have demonstrated that overexpression of LSD1 is involved in $\mathrm{PCa}$ initiation and progression. The androgen receptor (AR) signaling axis serves an important role in the organogenesis, morphology and normal functioning of the prostate (17). The vast majority of PCa cases express high levels of AR and showed androgen-dependent growth (3). Hence, androgen ablation via castration or administration of small chemical inhibitors is the most common treatment for advanced $\mathrm{PCa}(3)$. 
LSD1 forms chromatin-associated complexes with AR in a ligand-dependent manner and demethylates the repressing histone marks mono- and dimethyl H3-K9, thereby resulting in downregulation of AR target genes, including PSA $(14,16)$. PSA is a major prognostic factor for PCa (10). Therefore, the present study aimed to determine if downregulation of LSD1 expression could inhibit the AR signaling axis and enhance the efficacy of ADT for PCa.

\section{Materials and methods}

Cell culture. LNCaP cells were obtained from the Cell Bank of the Chinese Academy of Sciences. LNCaP cells were cultured in RPMI-1640 medium supplemented with 10\% FBS (Gibco; Thermo Fisher Scientific, Inc.) and $1 \%$ penicillin/streptomycin (Invitrogen; Thermo Fisher Scientific, Inc.) at $37^{\circ} \mathrm{C}$ in a humidified incubator in the presence of $5 \% \mathrm{CO}_{2}$.

Cell transfection. LNCaP cells were transfected with $10 \mathrm{nM}$ of small interfering (si)RNA for LSD1 (siRNA-LSD1-LNCaP; cat. no. sc-60970; Santa Cruz Biotechnology) or $10 \mathrm{nM}$ of scrambled siRNA control using Lipofectamine ${ }^{\circledR} 2000$ (cat. no. 11668027; Invitrogen; Thermo Fisher Scientific, Inc.), following themanufacturer'sinstructions.siRNA-LSD1-LNCaP (siRNA-LSD1 group) and normal LNCaP cells without treated with siRNA-LSD1 or scrambled siRNA (control group) were used $48 \mathrm{~h}$ following transfection for the subsequent experiments. The siRNA sequences against LSD1-1 were as follows: forward 5'-CGGACAAGCUGUUCCUAAA-3', reverse 3'-GC CUGUUCGACAAGGAUUU-5'; LSD1-2: forward 5'-GAA CUCCAUCAGCAAUACA-3', reverse 3'-CUUGAGGUAGU CGUUAUGU-5'.

Cell Counting Kit (CCK)-8 assay. The viability of the LNCaP cells was measured using CCK-8 (Boster Biological Technology) according to the manufacturer's instructions. The cells were seeded into a 96-well microplate at a density of $5 \times 103$ cells/well and incubated at $37^{\circ} \mathrm{C}$ for $24 \mathrm{~h}$. Then, the cells were incubated with or without bicalutamide $(20 \mu \mathrm{M})$ for 0,12 , 24 or 48 h. Finally, the absorbance of each well was measured at $490 \mathrm{~nm}$ using a Gemini XPS microplate reader (Molecular Devices, LLC).

Migration and invasion activity assay. The migration and invasion ability of siRNA-LSD1-LNCaP or LNCaP cells were evaluated using the modified Boyden chamber method. Cell migration assay was performed using Transwell inserts without Matrigel (24 wells, 8- $\mu$ m; cat. no. 354480; Corning Inc.). While, cell invasion assay was performed using Transwell inserts with Matrigel (24 wells, $8-\mu \mathrm{m}$; cat. no. 354480; Corning Inc.). For the invasion assay, $5 \times 10^{4}$ cells were suspended and plated on inserts pre-coated with Matrigel matrix at $37^{\circ} \mathrm{C}$ for $2 \mathrm{~h}$. Outer wells were set as a chemoattractant filling with $800 \mu \mathrm{l}$ RPMI-1640 containing 10\% FBS. After $48 \mathrm{~h}$ of incubation at $37^{\circ} \mathrm{C}(13)$, the invading cells were the cells on the undersurface of the filter which were fixed with paraformaldehyde at room temperature for $10 \mathrm{~min}$, stained with crystal violet at room temperature for $3 \mathrm{~min}$ and counted manually five fields per membrane under a light microscope (magnification, x400) (Olympus Corp.).
Flow cytometric analysis. The siRNA-LSD1-LNCaP or LNCaP cells $\left(5 \times 10^{5}\right.$ cells $\left./ \mathrm{ml}\right)$ were inoculated into 6 -well plates. Each group comprised of three double wells on the plate. Following 24-h incubation at $37^{\circ} \mathrm{C}$, the cells were treated with bicalutamide $(20 \mu \mathrm{M})$ and incubated at $37^{\circ} \mathrm{C}$ for an additional $24 \mathrm{~h}$. Flow cytometric analysis was performed according to the protocol of the Annexin V-Fluorescein Isothiocyanate Apoptosis Detection kit (Abcam). The apoptotic rates (included both early and late stages of apoptosis) were analyzed immediately using a FACSCalibur ${ }^{\mathrm{TM}}$ flow cytometer and BD FACSuite v.1.0.538.41 software (BD Biosciences). The data was analyzed using SPSS v.17.0 (SPSS, Inc.).

Xenograft tumor experiments. Xenograft tumors were established using early-passage cells and maintained in male NOD/SCID mice. A total of 40 male NOD/SCID mice (15-20 g) were used. All animals were obtained from Beijing Institute of Health Medicine and maintained in standard conditions according to the institutional guidelines. The Committee for Experimental Animals of Wuhan University (Wuhan, China) approved all experimental procedures, and the procedures complied with the Guidelines for the Care and Use of Laboratory Animals. For subcutaneous injection (s.c.) tumor growth, $5 \times 10^{7} \mathrm{LNCaP}$ cells (control group, $\mathrm{n}=20$ ) or siRNA-LSD1-LNCaP (siRNA-LSD1 group, $\mathrm{n}=20$ ) cells were suspended in $100 \mu \mathrm{l}$ of RPMI-1640 plus $100 \mu \mathrm{l}$ Matrigel (Collaborative Biomedical Products; BD Bioscience) and injected via a 27-gauge needle into the s.c. space of the back of the neck. Approximately 10 days after the LNCaP cells were injected into the NOD/SCID mice, palpable tumors were detected. Four weeks after the LNCaP cells were injected into the NOD/SCID mice, these mice were anesthetized with pentobarbital $(45 \mathrm{mg} / \mathrm{kg}$ ) and castrated (implemented with bilateral orchidectomy) using the scrotum incision approach. These mice were then sacrificed with cervical dislocation on day 8 after castration. Tumor tissues were fixed in $10 \%$ phosphate-buffered formalin at room temperature for $24 \mathrm{~h}$ or immediately frozen and stored at $-80^{\circ} \mathrm{C}$ for different procedures. Serial sections of $5-\mu \mathrm{m}$ were cut from the tissue blocks.

TUNEL assay. Apoptosis was examined using an TUNEL assay and an in situ Apoptosis Detection kit (Roche Applied Science). TUNEL reagent steps were performed at room temperature according to the manufacturer's instructions. Briefly, tumor tissues were fixed in $10 \%$ buffered formaldehyde at room temperature for a week, embedded in paraffin blocks and then sectioned at a thickness of $4-\mu \mathrm{m}$. Tissue sections were deparaffinized and rehydrated with xylene and an ethanol series (100, 90, 80 and 70\% ethanol) and treated with $20 \mu \mathrm{g} / \mathrm{ml}$ proteinase $\mathrm{K}$ at $37^{\circ} \mathrm{C}$ for $30 \mathrm{~min}$. TUNEL reaction mixture (50 $\mu \mathrm{l} /$ section) was added and incubated at $37^{\circ} \mathrm{C}$ for $1 \mathrm{~h}$. Converter-POD (50 $\mu \mathrm{l} / \mathrm{section})$ (1:500; anti-fluorescein antibody conjugated with horseradish peroxidase; cat. no. MK1025; BOSTER Biological Technology Co., Ltd) was added. Tissue sections were incubated at $37^{\circ} \mathrm{C}$ for $30 \mathrm{~min}$ and the signal was developed using $0.1 \%$ diaminobenzidine tetrahydrochloride for $5 \mathrm{~min}$. Tissue sections were dehydrated prior to mounting (Bio Optica Milano SpA). The nuclear stain used was diaminobenzidine (DAB). Cover specimen was treated with $100 \mu \mathrm{l}$ of diluted $\mathrm{DAB}$ solution and incubated at room temperature for $15 \mathrm{~min}$. 

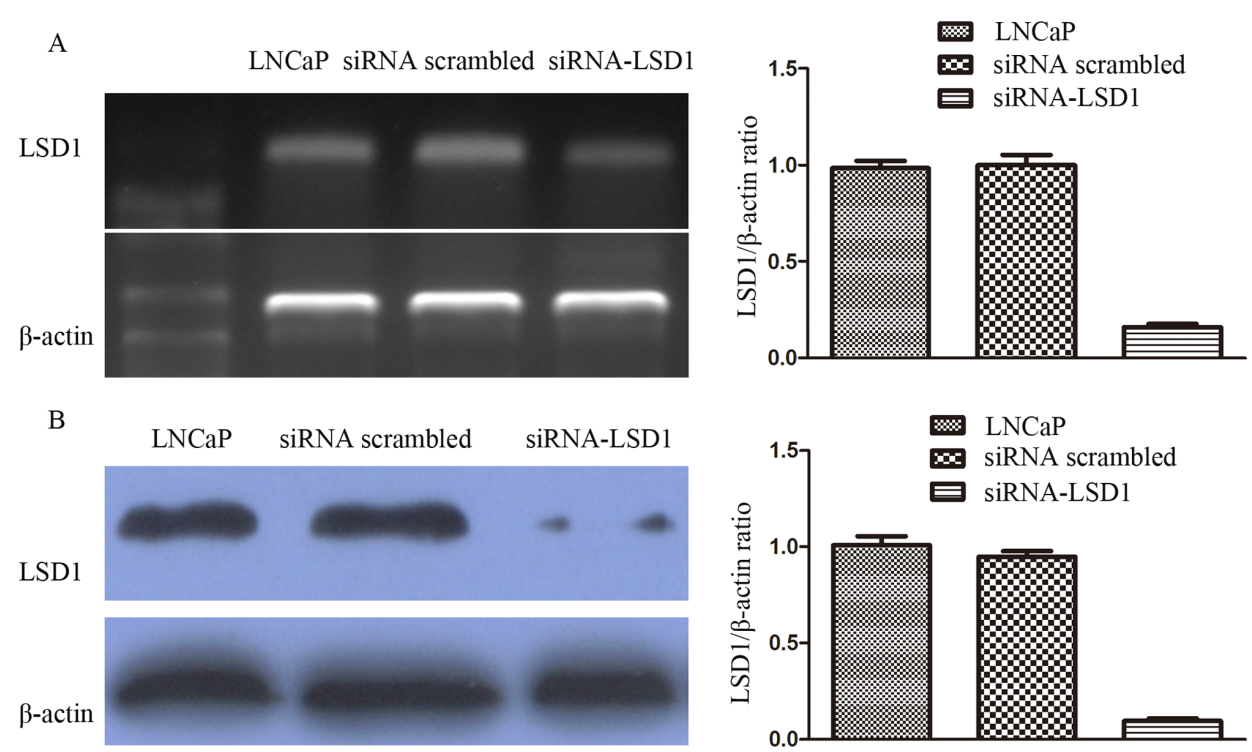

Figure 1. Transfection efficacy evaluated using RT-PCR and western blotting. (A) Level of LSD1 mRNA in LNCaP cells evaluated using RT-PCR. (B) Level of LSD1 protein in LNCaP cells was evaluated using western blotting. "P<0.05 vs. LNCaP. RT, reverse transcription; LSD1, lysine-specific demethylase 1; si, small interfering.

TUNEL-positive cells were identified by brown or tan staining of the nucleus. Five fields of light microscopy view (magnification, x200) were randomly selected and the apoptosis index was calculated as the ratio of apoptotic-to-total cells.

Reverse transcription (RT) semi-quantitative PCR. For gene expression studies RT-PCR was performed. Total RNA was isolated using TRIzol ${ }^{\circledR}$ reagent (Invitrogen; Thermo Fisher Scientific, Inc.), RNA concentration was obtained by spectrophotometer and reverse transcription was performed with the Revert Aid TM H Minus M-uLV Reverse Transcriptase kit (Fermentas; Thermo Fisher Scientific Inc.) according to the manufacturer's instructions. RNA was reverse transcribed into single-stranded cDNA at $70^{\circ} \mathrm{C}$ for 5 min using the cDNA synthesis kit (Takara Bio, Inc.) according to the manufacturer's procedures. The primers used were as follows: LSD-1, Forward: 5'-GCCCAAAGAAACTGTGGTGTC-3' and reverse: 5'-TGTGGC-TGGGTAGTTACGGAT-3'; $\beta$-actin, forward: 5'-CACCCAGCACAATGAAGATCAAGAT-3' and reverse: 5'-CCAGTTTTTAAATCCTGAGTCAAGC-3'. A total of 40 cycles of amplification was performed for each of the RT-PCR experiments. $\beta$-actin was amplified as an internal control. Initial denaturation was done at $94^{\circ} \mathrm{C}$ for $5 \mathrm{~min}$ followed by 35 cycles of amplification. Amplification protocol was repeated cycles of denaturation $\left(30 \mathrm{sec}, 94^{\circ} \mathrm{C}\right)$, annealing $\left(30 \mathrm{sec}, 56^{\circ} \mathrm{C}\right)$, extension $\left(1 \mathrm{~min}, 72^{\circ} \mathrm{C}\right)$ and final extension $\left(7 \mathrm{~min}, 72^{\circ} \mathrm{C}\right.$ ). Amplified products were analyzed on $1.5-3 \%$ agarose gels with Goldview staining at room temperature for 5 min (Beijing Baihao Biological Technology Company). Gels were visualized under UV light, photographed and optical densities of the bands were analyzed using Quantity One software version 4.6.6 (Bio-Rad, Laboratories Inc.).

Western blot analyses. The protein expression levels of LSD1, PSA, caspase-3, Bax and Bcl-2 were examined using western blotting. Briefly, the proteins (30-50 $\mu \mathrm{g} /$ lane) were loaded onto $8-12 \%$ gels, resolved using SDS-PAGE gels and then trans- ferred to nitrocellulose membranes (Bio-Rad Laboratories, Inc.). The membranes were blocked with 5\% non-fat milk in TBST buffer $(10 \mathrm{mmol} / 1$ Tris- $\mathrm{HCl}, 0.15 \mathrm{~mol} / \mathrm{l} \mathrm{NaCl}$ and $0.05 \%$ Tween-20, $\mathrm{pH}$ 7.2) for $2 \mathrm{~h}$ and incubated with primary antibodies overnight at $4{ }^{\circ} \mathrm{C}$. The primary antibodies used were monoclonal mouse antibodies against LSD1 (1:100; cat. no. 271720; Santa Cruz Biotechnology, Inc.) and monoclonal rabbit antibodies against PSA (1:800; cat. no. 5365; Cell Signaling Technology, Inc.), caspase 3 (1:1,000; cat. no. 9662), Bax (1:800; cat. no. 2772) and Bcl-2 (1:1,000; cat. no. 3498) (all Cell Signaling Technology, Inc.). After extensive washing with TBST buffer, the membranes were incubated with HRP-conjugated anti-mouse (1:2,000; cat. no. sc-516178) or anti-rabbit (1:2,000; cat. no. sc-2357) secondary antibodies (both 1:2,000; Santa Cruz Biotechnology, Inc.). The proteins were detected using an enhanced chemiluminescence system (ECL kit; Pierce; Thermo Fisher Scientific, Inc.) and captured on light-sensitive X-ray film (Kodak). Optical densities were detected using ImageJ software version 1.48 (National Institutes of Health).

Statistical analysis. Each sample was run in triplicates in 3 independent experiments. All data are presented as the mean \pm SEM. $\mathrm{P}<0.05$ was considered to indicate a statistically significant difference. The means of the different groups were compared using unpaired Student's t-test. Multiple comparisons were analyzed by one-way ANOVA followed by a Bonferroni's post hoc test. Categorical data were analyzed using Fisher's exact test. Statistical analysis was performed using SPSS 17.0 software (SPSS, Inc).

\section{Results}

Transfection efficiency analyzed using RT-PCR and western blotting. siRNA targeting LSD1 and scrambled siRNA were constructed and transfected into LNCaP cells, and then RT-PCR and western blotting were performed to evaluate 

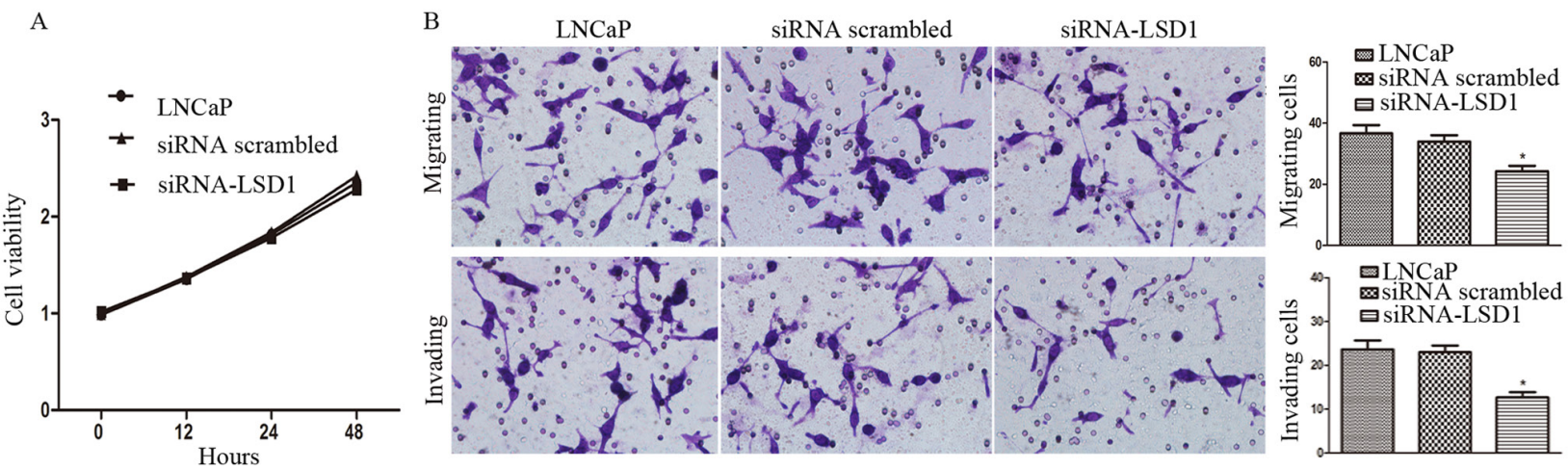

Figure 2. Effects of LSD1-knockdown on the proliferation and invasion of LNCaP cells. (A) LSD1-knockdown had no significant impact on the proliferation of LNCaP cells. (B) LSD1-knockdown significantly attenuated the migration and invasion of LNCaP cells. "P<0.05 vs. LNCaP. LSD1, lysine-specific demethylase 1; si, small interfering.
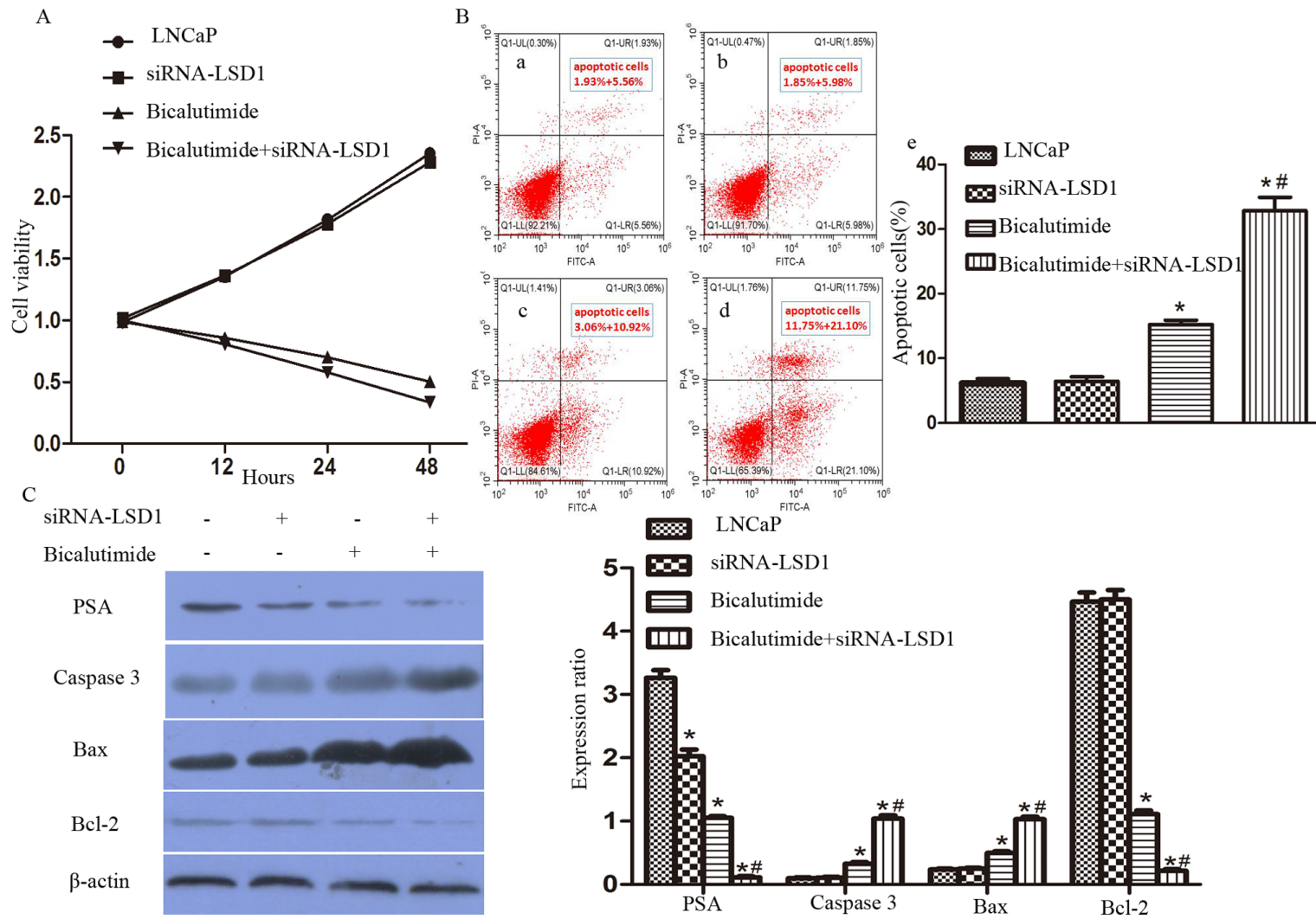

$\$$

$\mathrm{LNCaP}$

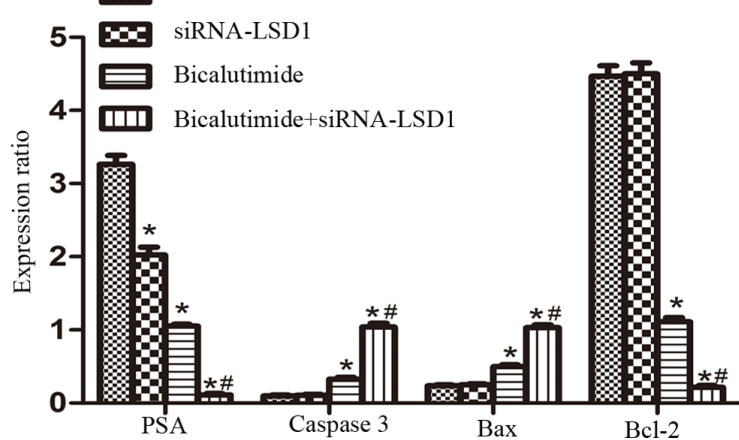

Figure 3. Effects of knockdown of LSD1 combined with bicalutamide on the proliferation and apoptosis of LNCaP cells. (A) LSD1-knockdown combined with bicalutamide treatment significantly decreased the proliferation of LNCaP cells. (B) Proportion of apoptotic cells in the LNCaP cells treated with siRNA increased significantly. (C) Expression levels of PSA, caspase 3, Bax and Bcl-2 were detected using western blotting after combination treatment of knockdown of LSD1 with bicalutamide for $24 \mathrm{~h} .{ }^{*} \mathrm{P}<0.05$ vs. LNCaP, ${ }^{\#} \mathrm{P}<0.05$ vs. bicalutamide. LSD1, lysine-specific demethylase 1 ; si, small interfering.

transfection efficiency. The results indicated that LSD1 mRNA levels were markedly downregulated in LNCaP treated with siRNA-LSD1 compared with those treated with scrambled siRNA and normal LNCaP cells (LNCaP vs. siRNA scrambled vs siRNA-LSD1: $0.98 \pm 0.04$ vs. $1.00 \pm 0.05$ vs. $0.16 \pm 0.02$; $\mathrm{P}<0.05$; Fig. 1A). The results also indicated that LSD1 protein levels were markedly downregulated in LNCaP treated with siRNA-LSD1 compared with those treated with scrambled siRNA and normal LNCaP cells (LNCaP vs. siRNA scrambled vs. siRNA-LSD1: $1.01 \pm 0.05$ vs. $0.95 \pm 0.03$ vs. $0.10 \pm 0.01$; $\mathrm{P}<0.05$; Fig. 1B).
Knockdown of LSD1 attenuates the invasion ability of LNCaP cells. Without bicalutamide treatment, LSD1-knockdown had no significant impact on proliferation of LNCaP cells $(\mathrm{P}>0.05$; Fig. 2A). Furthermore, the effect of LSD1-knockdown on the LNCaP cell migration and invasion was examined using the Boyden chamber invasion assay. LSD1-knockdown (siRNA-LSD1 group) significantly attenuated the migration $(\mathrm{P}<0.05)$ and invasion $(\mathrm{P}<0.05)$ of $\mathrm{LNCaP}$ cells, compared with LNCaP group and siRNA scrambled group, as shown in Fig. 2B, consistent with the findings of our previous study via inhibition of LSD1 by its inhibitor pargyline (13). 
Table I. Effects of LSD1 on tumorigenicity and tumor size.

\begin{tabular}{lrrrcr}
\hline & \multicolumn{2}{c}{ Tumorigenicity } & & & \\
\cline { 2 - 5 } Group & Yes & No & P-value & Tumor size, $\mathrm{mm}^{3}$ & P-value \\
\hline LNCaP & 15 & 5 & 0.02 & $813 \pm 6$ & 0.60 \\
siRNA-LSD1 & 7 & 13 & & $807 \pm 12$ & \\
\hline
\end{tabular}

LSD1, lysine-specific demethylase 1.
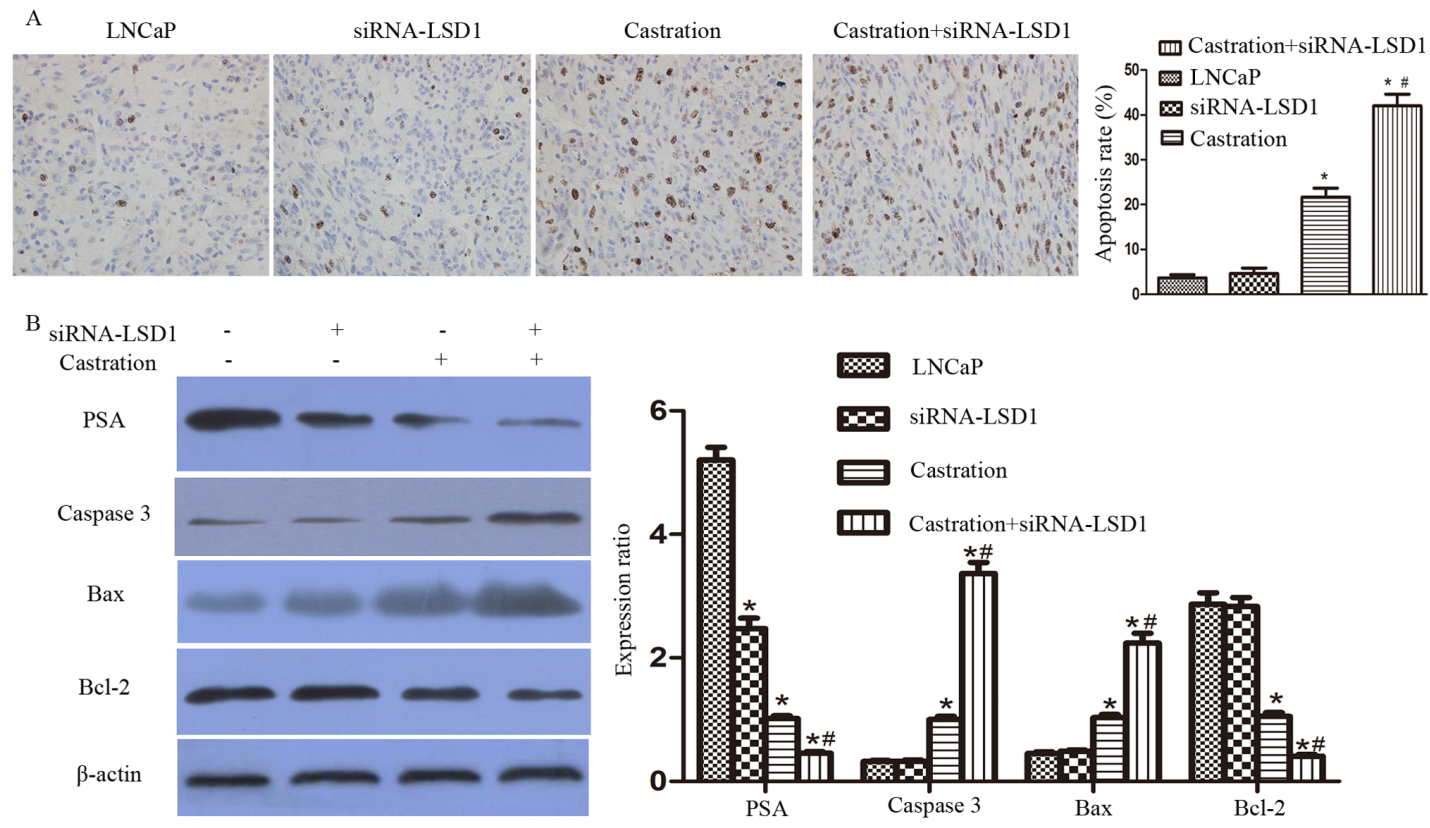

Figure 4. Effects of knockdown of LSD1 combined with castration on the apoptosis of LNCaP xenograft tumors and western blot analysis. (A) Proportion of apoptotic cells in tumor tissues was assessed using TUNEL assays. (B) Expression of PSA, caspase 3, Bax and Bcl-2 affected by castration treatment combined with LSD1-knockdown was detected using western blot analyses. ${ }^{*} \mathrm{P}<0.05$ vs. LNCaP, ${ }^{,} \mathrm{P}<0.05$ vs. castration. LSD1, lysine-specific demethylase 1 ; si, small interfering.

Knockdown of LSD1 enhances the bicalutamide-induced apoptosis of LNCaP cells. Combined with bicalutamide treatment, LSD1-knockdown (Bicalutimide + siRNA-LSD1 group) significantly decreased the proliferation of LNCaP cells, compared with LNCaP group, siRNA scrambled group and bicalutimide group $(\mathrm{P}<0.05$; Fig. 3$)$. Annexin V/PI-stained flow cytometric analysis was used to determine whether the decreased cell viability was due to apoptosis. The proportion of apoptotic cells treated with bicalutamide increased significantly for the cells treated with siRNA compared with the normal LNCaP cells (bicalutamide group vs. bicalutamide+siRNA-LSD1 group, $16.78 \pm 0.90$ vs. $33.16 \pm 2.16 \%$, respectively ( $\mathrm{P}<0.05$; Fig. 3 ). Moreover, PSA and the apoptosis-associated proteins caspase 3, Bax and Bcl-2 were detected using western blot analyses (Fig. 3). Bicalutamide treatment combined with LSD1-knockdown in the LNCaP cells (Bicalutimide + siRNA-LSD1 group) resulted in downregulation of PSA $(\mathrm{P}<0.05)$, upregulation of caspase $3(\mathrm{P}<0.05)$ and $\mathrm{Bax}$ $(\mathrm{P}<0.05)$ and downregulation of $\mathrm{Bcl}-2(\mathrm{P}<0.05)$ compared with the LNCaP group, siRNA scrambled group and bicalutimide group.
Knockdown of LSD1 decreases the tumorigenicity of LNCaP cells but has no significant impact on tumor growth. Palpable tumors weredetected in $75 \%$ of theNOD/SCID mice 3 weeks after injection of the control LNCaP cells (LNCaP group). However, palpable tumors were detected in only $35 \%$ of the NOD/SCID mice 3 weeks after injection of the siRNA-LSD1-LNCaP cells (siRNA-LSD1 group). In the siRNA-LSD1 group, the tumor sizes were not significantly different from those in the LNCaP group (LNCaP group vs. siRNA-LSD1 group: $813 \pm 6$ vs. $807 \pm 12 \mathrm{~mm}^{3} ; \mathrm{P}=0.60$; Table I), and there were no significant differences in the maximum diameter of each tumor during between LNCaP group (9.5-13.5 mm) and siRNA-LSD1 group $(9-14 \mathrm{~mm})(\mathrm{P}>0.05$; Fig. S1).

Knockdown of LSD1 enhances the castration-induced apoptosis of $\mathrm{LNCaP}$ cells. Four weeks after injection of the LNCaP cells, the mice with xenograft tumors were castrated via a bilateral orchidectomy. These mice were then sacrificed on day 8 after castration. The tumor tissues were used for the TUNEL assays and western blot analyses. Consistent with the in vitro results of the present study, the proportion of apoptotic cells in the tumor tissues treated with castration and siRNA-LSD1 
(Bicalutimide + siRNA-LSD1 group) increased significantly compared with the LNCaP group, siRNA-LSD1 group and castration group $(\mathrm{P}<0.05$; Fig. 4). Castration treatment combined with LSD1-knockdown (Bicalutimide + siRNA-LSD1 group) showed significant downregulation of PSA, upregulation of caspase 3 and Bax and downregulation of Bcl-2, compared with the LNCaP group, siRNA-LSD1 group and castration group ( $\mathrm{P}<0.05$; Fig. 4).

\section{Discussion}

The present study demonstrated that knockdown of LSD1 could effectively inhibit the invasion of LNCaP cells. Moreover, knockdown of LSD1 combined with bicalutamide further decreased PSA expression and proliferation and promoted apoptosis of LNCaP cells in vitro. Furthermore, it was observed that knockdown of LSD1 combined with castration enhanced the apoptosis of LNCaP implant tumor cells, downregulating the expression of PSA and Bcl-2 and upregulating the expression of caspase 3 and Bax.

$\mathrm{AR}$ is a steroid receptor and a member of the larger nuclear receptor superfamily of proteins (18). The AR signaling pathway plays a central role in normal prostate development and in PCa initiation and progression (18). The exact roles of $\mathrm{AR}$ in PCa are still unclear, but AR is involved in stimulating the expression of a series of genes, such as cyclin D proteins, mTOR and retinoblastoma tumor suppressor protein, that regulate the PCa cell cycle, proliferation and survival $(19,20)$. In the early stage PCa cells are dependent on androgens for proliferation $(3,18)$. Therefore, ADT has been well accepted as the standard treatment for patients with no indications of radical prostatectomy (18).

LSD1 is involved in numerous pathological processes of cancer, such as carcinogenesis, proliferation, apoptosis and metastasis $(21-25)$. Notably, multiple studies $(14,16,26)$ have demonstrated that LSD1 is a critical AR coregulator and plays a key role in regulating AR signaling through its activator function. These findings provided a strong molecular basis for knockdown of LSD1 expression or LSD1 inhibitors to treat PCa. Hence, the present study investigated the effect of the combination of ADT with knockdown of LSD1 in preclinical models of hormone-sensitive PCa using LNCaP cells and LNCaP xenograft tumors.

AR signaling regulates the transcription of protein products that are required for prostate function, including PSA $(10,18)$. PSA is still the most commonly used factor for PCa diagnosis, prognosis and follow-up $(10,14,16)$. The current study showed that LSD1-knockdown, combined with bicalutamide treatment, significantly decreased the expression of PSA in LNCaP cells. Furthermore, these results demonstrated that LSD1-knockdown, combined with castration, significantly reduced the expression of PSA in LNCaP xenograft tumors.

Apoptosis is characterized by a series of physiological and pathological changes, such as cytoplasmic blebbing, chromatin condensation and DNA fragmentation, which might be induced by numerous different stimuli (27). Hormone-sensitive PCa cells are dependent on AR signaling and are sensitive to AR antagonists $(3,18)$. Bicalutamide, the most commonly used AR antagonist, effectively induces the apoptosis of PCa cells (3). Members of the Bcl-2 family $(28,29)$, including Bax and Bcl-2, play a key role in monitoring the mitochondrial pathway of apoptosis. Furthermore, caspase 3 has been recognized as a critical downstream effector of apoptosis (30). The present study reported that knockdown of LSD1, combined with an AR antagonist in vitro or with castration in vivo, could significantly promote apoptosis of PCa cells, inhibit the expression of the antiapoptotic $\mathrm{Bcl}-2$ protein, and increase the levels of the proapoptotic proteins Bax and caspase-3 in vitro and in vivo.

The present experiments were conducted using only one cell line, LNCaP, which is a limitation of the present study, and use of clinical prostate cancer tissues or other cell lines may not necessarily result in the same outcomes. The VCaP and C4-2 cell lines should be used in future to validate the present findings.

LSD1 functions as a transcriptional coregulator of AR to enhance transcriptional activation or suppression of target genes in a ligand-dependent manner $(14,16,31)$. The present results showed that knockdown of LSD1 could further downregulate PSA expression and increase apoptosis of $\mathrm{LNCaP}$ cells induced by bicalutamide in vitro, and enhance the apoptosis of LNCaP xenograft tumor cells induced by castration. In conclusion, knockdown of LSD1 expression might serve as a potential therapeutic intervention to enhance the efficacy of ADT for $\mathrm{PCa}$ by repressing AR signaling and promoting apoptosis.

\section{Acknowledgements}

Not applicable.

\section{Funding}

This study was supported by grants from The National Natural ScienceFoundation of China (grant no. 81972408), The Province Natural Science Foundation of Hubei (grant no. 2019CFB302), The Province Natural Science Foundation of Hubei (grant no. 2016CFB 114), The Science Foundation of Wuhan (grant no. 20150601010100 49), The Application and Basic Research Project Of Wuhan City (grant no. 2018060401011321) and supported by the Fundamental Research Funds for the Central Universities (grant no. 2042017kf0089).

\section{Availability of data and materials}

The datasets analyzed during the current study are available from the corresponding author on reasonable request.

\section{Authors' contributions}

MW and XL conducted the experiments, analyzed the data, and supervised and wrote the manuscript. MW, ZC and LZ conducted the experiments and analyzed the data. MW, XW and LZ performed the experiments and collated the data from them and performed the statistical analysis. XL helped to design the study and interpreted data. All the authors read and approved the final version of the manuscript.

\section{Ethics approval and consent to participate}

The present study was approved by The Ethics Committee of the Renmin Hospital of Wuhan University (Wuhan, 
China). Informed consent was obtained from all participants (approval no. RM2018Y018-06). All animal study protocols were approved by The Institutional Animal Use and Care Committee of China Medical University (Shenyang, China).

\section{Patient consent for publication}

Not applicable.

\section{Competing interests}

The authors declare that they have no competing interests.

\section{References}

1. Ferlay J, Soerjomataram I, Dikshit R, Eser S, Mathers C, Rebelo M, Parkin DM, Forman D and Bray F: Cancer incidence and mortality worldwide: Sources, methods and major patterns in GLOBOCAN 2012. Int J Cancer 136: E359-E386, 2015.

2. Chen W, Zheng R, Zeng H, Zou X, Zhang S and He J: Report of Cancer Incidence and Mortality in China, 2011. China Cancer 24 $1-10,2012$.

3. Larsson R, Mongan NP, Johansson M, Shcherbina L, Abrahamsson PA, Gudas LJ, Sterner O and Persson JL: Clinical trial update and novel therapeutic approaches for metastatic prostate cancer. Curr Med Chem 18: 4440-4453, 2011.

4. 4. Rice MA, Malhotra SV and Stoyanova T: Second-Generation Antiandrogens: From Discovery to Standard of Care in Castration Resistant Prostate Cancer. Front Oncol 9: 801, 2019.

5. 5. Tannock IF, de Wit R, Berry WR, Horti J, Pluzanska A, Chi KN, Oudard S, Théodore C, James ND, Turesson I, et al; TAX 327 Investigators: Docetaxel plus prednisone or mitoxantrone plus prednisone for advanced prostate cancer. N Engl J Med 351: 1502-1512, 2004.

6. Scher HI, Morris MJ, Stadler WM, Higano C, Basch E, Fizazi K, Antonarakis ES, Beer TM, Carducci MA, Chi KN, et al: Tria design and objectives for castration-resistant prostate cancer: updated recommendations from the prostate cancer clinical trials working group 3. J Clin Oncol 34: 1402-1418, 2016.

7. Higano CS, Beer TM, Taplin ME, Efstathiou E, Hirmand M, Forer D and Scher HI: Long-term safety and antitumor activity in the Phase1-2 study of enzalutamide in pre- and post-docetaxe castration-resistant prostate cancer. Eur Urol 68: 795-801, 2015.

8. Ryan CJ, Smith MR, de Bono JS, Molina A, Logothetis CJ, de Souza P, Fizazi K, Mainwaring P, Piulats JM, Ng S, et al; COU-AA-302 Investigators: Abiraterone in metastatic prostate cancer without previous chemotherapy. N Engl J Med 368: 138-148, 2013.

9. Ryan CJ, Smith MR, Fizazi K, Saad F, Mulders PF, Sternberg CN, Miller K, Logothetis CJ, Shore ND, Small EJ, et al; COU-AA-302 Investigators: Abiraterone acetate plus prednisone versus placebo plus prednisone in chemotherapy-naive men with metastatic castration-resistant prostate cancer (COU-AA-302): Final overall survival analysis of a randomised, double-blind, placebo-controlled phase 3 study. Lancet Oncol 16: 152-160, 2015.

10. Hussain M, Tangen CM, Higano C, Schelhammer PF, Faulkner J, Crawford ED, Wilding G, Akdas A, Small EJ, Donnelly B, et al; Southwest Oncology Group Trial 9346 (INT-0162): Absolute prostate-specific antigen value after androgen deprivation is a strong independent predictor of survival in new metastatic prostate cancer: Data from Southwest Oncology Group Trial 9346 (INT-0162). J Clin Oncol 24: 3984-3990, 2006.

11. Shi Y, Lan F, Matson C, Mulligan P, Whetstine JR, Cole PA, Casero RA and Shi Y: Histone demethylation mediated by the nuclear amine oxidase homolog LSD1. Cell 119: 941-953, 2004.

12. Wang M, Liu X, Jiang G, Chen H, Guo J and Weng X: Relationship between LSD1 expression and E-cadherin expression in prostate cancer. Int Urol Nephrol 47: 485-490, 2015.

13. Wang M, Liu X, Guo J, Weng X, Jiang G, Wang Z and He L: Inhibition of LSD1 by Pargyline inhibited process of EMT and delayed progression of prostate cancer in vivo. Biochem Biophys Res Commun 467: 310-315, 2015.
14. Metzger E, Wissmann M, Yin N, Müller JM, Schneider R, Peters AH, Günther T, Buettner R and Schüle R: LSD1 demethylates repressive histone marks to promote androgen-receptor-dependent transcription. Nature 437: 436-439, 2005.

15. Metzger E, Imhof A, Patel D, Kahl P, Hoffmeyer K, Friedrichs N, Müller JM, Greschik H, Kirfel J, Ji S, et al: Phosphorylation of histone H3T6 by PKCbeta(I) controls demethylation at histone H3K4. Nature 464: 792-796, 2010.

16. Kahl P, Gullotti L, Heukamp LC, Wolf S, Friedrichs N, Vorreuther R, Solleder G, Bastian PJ, Ellinger J, Metzger E, et al: Androgen receptor coactivators lysine-specific histone demethylase 1 and four and a half LIM domain protein 2 predict risk of prostate cancer recurrence. Cancer Res 66: 11341-11347, 2006.

17. Schaeffer EM, Marchionni L, Huang Z, Simons B, Blackman A, Yu W, Parmigiani G and Berman DM: Androgen-induced programs for prostate epithelial growth and invasion arise in embryogenesis and are reactivated in cancer. Oncogene 27: 7180-7191, 2008.

18. Green SM, Mostaghel EA and Nelson PS: Androgen action and metabolism in prostate cancer. Mol Cell Endocrinol 360: 3-13, 2012.

19. Knudsen KE, Arden KC and Cavenee WK: Multiple G1 regulatory elements control the androgen-dependent proliferation of prostatic carcinoma cells. J Biol Chem 273: 20213-20222, 1998.

20. Xu Y, Chen SY, Ross KN and Balk SP: Androgens induce prostate cancer cell proliferation through mammalian target of rapamycin activation and post-transcriptional increases in cyclin D proteins. Cancer Res 66: 7783-7792, 2006.

21. Huang J, Sengupta R, Espejo AB, Lee MG, Dorsey JA, Richter M, Opravil S, Shiekhattar R, Bedford MT, Jenuwein T, et al: p53 is regulated by the lysine demethylase LSD1. Nature 449: 105-108, 2007.

22. Scoumanne A and Chen X: The lysine-specific demethylase 1 is required for cell proliferation in both p53-dependent and -independent manners. J Biol Chem 282: 15471-15475, 2007.

23. Schulte JH,Lim S, Schramm A, Friedrichs N, Koster J, Versteeg R, Ora I, Pajtler K, Klein-Hitpass L, Kuhfittig-Kulle S, et al: Lysine-specific demethylase 1 is strongly expressed in poorly differentiated neuroblastoma: Implications for therapy. Cancer Res 69: 2065-2071, 2009.

24. Hayami S, Kelly JD, Cho HS, Yoshimatsu M, Unoki M, Tsunoda T, Field HI, Neal DE, Yamaue H, Ponder BA, et al: Overexpression of LSD1 contributes to human carcinogenesis through chromatin regulation in various cancers. Int J Cancer 128: 574-586, 2011.

25. Bennani-Baiti IM, Machado I, Llombart-Bosch A and Kovar H: Lysine-specific demethylase 1 (LSD1/KDM1A/AOF2/BHC110) is expressed and is an epigenetic drug target in chondrosarcoma, Ewing's sarcoma, osteosarcoma, and rhabdomyosarcoma. Hum Pathol 43: 1300-1307, 2012.

26. Cai C, He HH, Gao S, Chen S, Yu Z, Gao Y, Chen S, Chen MW, Zhang J, Ahmed M, et al: Lysine-specific demethylase 1 has dual functions as a major regulator of androgen receptor transcriptional activity. Cell Rep 9: 1618-1627, 2014.

27. McConkey DJ, Orrenius S and Jondal M: Cellular signalling in programmed cell death (apoptosis). Immunol Today 11: 120-121, 1990.

28. Strobel T, Swanson L, Korsmeyer S and Cannistra SA: BAX enhances paclitaxel-induced apoptosis through a p53-independent pathway. Proc Natl Acad Sci USA 93: 14094-14099, 1996.

29. Antonsson B and Martinou JC: The Bcl-2 protein family. Exp Cell Res 256: 50-57, 2000.

30. Gross A, McDonnell JM and Korsmeyer SJ: BCL-2 family members and the mitochondria in apoptosis. Genes Dev 13: 1899-1911, 1999

31. Lin T, Ponn A, Hu X, Law BK and Lu J: Requirement of the histone demethylase LSD1 in Snail-mediated transcriptional repression during epithelial-mesenchymal transition. Oncogene 29: 4896-4904, 2010.

This work is licensed under a Creative Commons Attribution-NonCommercial-NoDerivatives 4.0 International (CC BY-NC-ND 4.0) License. 